\title{
Métodos para desenvolvimento de softwares e sua relação com questões de gênero na Grande Florianópolis
}

\author{
Software development methods and gender issues in Florianópolis (Brazil)
}

\author{
SCHVEITZER, Audrey Schmitz; Mestranda em Design; Universidade do Estado de Santa Catarina \\ (UDESC) \\ audreysschmitz@gmail.com \\ SANTOS, Flávio Anthero Nunes Vianna; Prof. Dr.; Universidade do Estado de Santa Catarina \\ (UDESC) \\ flavioanvs@hotmail.com \\ SANTOS, Celio Teodorico; Prof. Dr.; Universidade do Estado de Santa Catarina (UDESC) \\ celio.teodorico@gmail.com
}

\section{Resumo}

Esta pesquisa objetiva analisar a composição das equipes de desenvolvimento de softwares situadas na Grande Florianópolis e os métodos projetuais utilizados por estas, de forma a identificar possíveis direcionamentos dos softwares, no que diz respeito às questões de gênero, bem como verificar se há o intuito de as empresas desenvolverem produtos para gêneros específicos. Realizou-se uma revisão bibliográfica para embasar a aplicação de um questionário digital respondido por profissionais da área de interesse, entre novembro de 2017 e março de 2018. Com isso, foi possível perceber que as empresas possuem um quadro societário, de gestão e de colaboradores predominantemente masculino; que têm dificuldade em garantir a participação do público-alvo nos projetos, entre outros fatores que possibilitam o desenvolvimento de softwares com viés masculino, ainda que os profissionais não tenham essa intenção e busquem atender, na maioria dos projetos, a um público de gênero neutro.

Palavras Chave: método projetual; desenvolvimento de software; questões de gênero.

\begin{abstract}
This research aims to analyze the composition of the software development teams located in the Florianópolis region and the design methods used by them, in order to identify possible software orientations regarding gender issues, as well to verify if there is the intention of companies to develop products for specific genres. A bibliographic review was carried out to support the application of a digital questionnaire answered by professionals of the area of interest between November 2017 and March 2018. With this, it was possible to perceive that the companies have a predominantly masculine corporate structure from the management to collaborators; also have difficulty in ensuring the participation of the target audience in the projects, among other factors that allow the development of softwares with a male bias, even though the professionals do not intend this and the target audience is seen as gender neutral.
\end{abstract}

Keywords: design method; software development; gender issues. 


\section{Introdução}

Estudos a respeito do ser humano e o uso das tecnologias expandiram-se drasticamente na última década de pesquisa, na área de Fatores Humanos, mais especificamente em Interação Humano-Computador (IHC), como apontam Schlesinger et al. (2017). Para os autores, com os estudos em IHC surgiram também os questionamentos a respeito da representação do chamado usuário e o emprego de tal termo para designar um sujeito comum. Tais questionamentos, segundo os autores, motivaram outros campos de estudo que visaram abordar o usuário como um sujeito complexo, com motivações, sentimentos e identidades próprias. Dentre os aspectos que constroem a identidade dos sujeitos, pode-se incluir também os de gênero, aqui compreendido, em linhas gerais, como "(...) uma categoria usada para pensar as relações sociais que envolvem homens e mulheres, relações historicamente determinadas e expressas pelos diferentes discursos sociais sobre a diferença sexual" (GROSSI, 2010, p. 5).

No que se refere ao desenvolvimento de produtos, um dos fatores-chave é a definição do público-alvo, cujos indivíduos são diferenciados, entre outros fatores, por idade e gênero. Ao se desenvolver produtos especificamente para um gênero, de qualquer faixa etária, muitas empresas se contentam com estratégias rasas, como a diferenciação de produtos pela cor (como roupas azuis para meninos e rosas para meninas). Uma dessas estratégias é conhecida como shrink it and pink it, na qual a lógica para se fazer uma versão feminina de um produto se restringe a deixá-lo menor e a pintá-lo de cor-de-rosa. A mesma estratégia pode ser observada na indústria tecnológica e na de software, em brinquedos, em jogos desenvolvidos para meninas ou aplicativos direcionados para mulheres, enquadrados no que se denominou de pink technology e pink software (KEARNEY, 2010). No entanto, há outras empresas que buscam intencionalmente desenvolver produtos de gênero neutro, ou seja, que possam atender igualmente às necessidades de indivíduos de qualquer gênero.

A problemática do desenvolvimento de produtos e sua relação com as questões de gênero é estudada por diversos autores, como Churchill (2010), Kearney (2010), Bardzell (2011), Breslin e Wadhwa (2014), Dray (2014), Burnett et al. (2015), Ratzer (2017) e Schlesinger (2017), entre outros. Williams (2014) aborda especificamente o desenvolvimento de softwares e levanta diversos questionamentos a respeito do projeto de softwares de gênero neutro. Para a autora, o fato de um produto ser desenvolvido com o objetivo de ser neutro não garante que ele efetivamente o seja. Williams (2014) ressalta ainda que a baixa taxa de participação de mulheres nas equipes de desenvolvimento tecnológico, nas posições decisórias e de chefia, são fatores preponderantes que dificultam o desenvolvimento de produtos que possam atender às necessidades tanto de homens quanto de mulheres. Segundo ela, as mulheres ocupam cerca de $20 \%$ dos postos de trabalho em desenvolvimento de softwares nos Estados Unidos, número semelhante ao do setor tecnológico brasileiro (que inclui o desenvolvimento de softwares), no qual as mulheres ocupam entre $18,5 \% \mathrm{e}$ 19,5\% dos postos de trabalho do setor, segundo Olinto (2011), Castro (2013) e Horta Nunes (2016). Churchill (2010) corrobora tal pensamento e afirma que as decisões de projeto tendem a pender para aquilo que parece mais compreensível, confortável ou familiar para os membros da equipe, e pelo fato de a maioria das equipes de desenvolvimento de produtos tecnológicos serem formadas por homens, são assim criados a partir de uma visão masculina de mundo.

Para Williams (2014), ainda que o fator da desigualdade na participação das mulheres nas equipes de desenvolvimento de softwares seja relevante e necessite atenção, não se pode esperar igualdade na composição das equipes para que só então se passe a viabilizar maneiras de garantir que produtos sejam desenvolvidos, com sucesso, também para as mulheres. Assim, a autora levanta 
algumas questões a serem observadas para diminuir os vieses de gênero no desenvolvimento de softwares, como a composição das equipes, as posições hierárquicas, os meios de comunicação disponibilizados e os métodos para a tomada de decisão. Para elencar tais questões, a autora realizou uma série de entrevistas com profissionais de ambos os sexos, com diferentes cargos e funções de uma empresa desenvolvedora de softwares, a fim de analisar como as percepções pessoais desses profissionais influenciam seu trabalho e o potencial impacto dessa influência no desenvolvimento de produtos, no que diz respeito ao gênero.

A partir de tais apontamentos, considerou-se relevante investigar uma possível relação entre o cenário observado por Williams (2014), nos Estados Unidos, e o cenário de desenvolvimento de softwares brasileiro, mais especificamente na Grande Florianópolis ${ }^{1}$, em Santa Catarina. Tal opção deu-se pela relevante participação da atividade tecnológica na economia da região, além de sua representatividade nos mercados estadual e nacional. De acordo com a Associação Catarinense de Empresas de Tecnologia (Acate), o setor de tecnologia de Santa Catarina possui a maior densidade de funcionários do país, cerca de 2.891 a cada 100 mil habitantes (ACATE, 2016). De acordo com a Associação, existem aproximadamente 2,9 mil empresas de Tecnologia da Informação (TI) no estado de Santa Catarina, empregando cerca de 50 mil pessoas. Destas empresas, cerca de 900, o equivalente a 31\%, encontra-se na Grande Florianópolis (ACATE, 2016). O faturamento do setor no estado é de aproximadamente R\$ 11 bilhões, o que corresponde 5\% do PIB estadual. O polo de Florianópolis é o líder em Santa Catarina e o terceiro maior do Brasil em faturamento médio, ficando atrás de Campinas (SP) e do Rio de Janeiro (RJ), e à frente de grandes cidades como São Paulo (SP), Porto Alegre (RS) e Brasília (DF).

Com relação à composição das empresas de tecnologia catarinenses, de acordo com a Acate (2016), empreendedores do setor têm idade média de 42 anos, sendo 74,5\% deles do sexo masculino e $25,5 \%$ do sexo feminino. Dentre os colaboradores, por sua vez, a idade média é de 32 anos, sendo que $61,6 \%$ são do sexo masculino e $38,4 \%$ do sexo feminino. Tais números demonstram que a participação das mulheres no mercado de tecnologia em Santa Catarina é maior em relação à média nacional e a média norte-americana (que giram em torno de $20 \%$ ), mas que ainda há uma grande disparidade entre os sexos na composição destas empresas. A partir deste cenário, pode-se questionar se a composição das empresas poderia influenciar na maneira com que elas desenvolvem seus produtos, no que diz respeito às questões de gênero, e se a participação feminina, em Santa Catarina, seria suficiente para diferenciar o cenário de desenvolvimento de software, se comparado ao que foi percebido por Williams (2014), nos Estados Unidos.

Desta forma, esta pesquisa visa analisar a composição das equipes de desenvolvimento de softwares em empresas privadas da Grande Florianópolis e os métodos projetuais utilizados por elas, de forma a compreender possíveis impactos no direcionamento de seus softwares, com relação às questões de gênero, bem como verificar se há o intuito, por parte das empresas, de desenvolver produtos para gêneros específicos.

\subsection{Metodologia}

\footnotetext{
${ }^{1}$ Foi adotada a expressão "Grande Florianópolis" devido ao seu uso popular, mas nos referimos à Microrregião de Florianópolis que engloba, além da capital Florianópolis, os municípios de Antônio Carlos, Biguaçu, Governador Celso Ramos, Palhoça, Paulo Lopes, Santo Amaro da Imperatriz, São José e São Pedro de Alcântara, no Estado de Santa Catarina.
} 
A fim de se atingir o objetivo proposto, partiu-se de uma revisão bibliográfica sistematizada na base de dados Scopus, efetuada entre 15 de outubro e 16 de novembro de 2017. Foram utilizados 3 strings de busca ${ }^{2}$, indo de um mais restrito para um mais amplo, buscando-se incluir temas como métodos de projeto, desenvolvimento de software e questões de gênero, como descrito no quadro a seguir:

Quadro 1 - Fontes e strings da revisão bibliográfica sistematizada.

\begin{tabular}{|c|c|c|c|}
\hline Base & String de pesquisa & $\begin{array}{l}\text { Resultados } \\
\text { obtidos }\end{array}$ & $\begin{array}{l}\text { Trabalhos } \\
\text { selecionados }\end{array}$ \\
\hline \multirow[t]{3}{*}{ Scopus } & 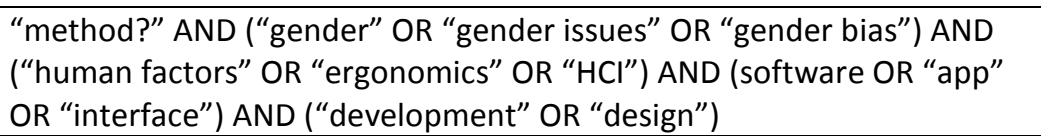 & 20 & 4 \\
\hline & $\begin{array}{l}\text { "method?" AND (“human factors" OR “ergonomics” OR “HCl”) AND } \\
\text { (software OR “app" OR “interface”) AND ("development" OR “design”) - } \\
\text { agregados aos filtros de ano (a partir de 2012), língua (inglês e português) } \\
\text { e área (Social Sciences e Arts and Humanities) }\end{array}$ & 119 & 9 \\
\hline & $\begin{array}{l}\text { (“gender" OR "gender issues" OR “gender bias") AND (software OR “app" } \\
\text { OR "interface") AND (“development" OR “design") - agregados aos filtros } \\
\text { de ano (a partir de 2012), língua (inglês e português) e área (Computer } \\
\text { Science, Social Sciences, Business, Arts and Humanities, Decision Sciences, } \\
\text { Multidisciplinary) }\end{array}$ & 279 & 18 \\
\hline
\end{tabular}

Fonte: Elaboração dos autores.

Dentre os trabalhos selecionados durante a revisão bibliográfica, o trabalho de Williams (2014) serviu como referencial para a segunda fase da pesquisa, relativa à coleta de dados. Esta foi efetuada por meio de um questionário, inicialmente validado por um profissional da área de desenvolvimento de softwares e posteriormente distribuído em meio digital, respondido por 30 profissionais que participam de equipes de desenvolvimento de softwares em empresas privadas situadas na Grande Florianópolis, entre novembro de 2017 e março de 2018. Fontes externas, como o relatório da Associação Catarinense de Empresas de Tecnologia (ACATE, 2016) e bibliografias a respeito de questões de gênero também foram utilizadas.

O questionário ${ }^{3}$ de 31 perguntas foi estruturado em três eixos: (1) dados pessoais, (2) dados da empresa e (3) dados sobre o desenvolvimento de softwares na empresa. Com o intuito de evitar constrangimentos, optou-se por não solicitar a identificação nominal dos indivíduos e da empresa onde trabalham. Quanto aos dados pessoais, foram coletadas informações relativas à: idade, gênero, local de residência, escolaridade, profissão, característica do cargo que ocupa (se é decisório ou não) e experiência profissional em desenvolvimento de software. Com relação à empresa, solicitaram-se dados quanto à sua localização (para confirmar se estão situadas na Grande Florianópolis), número aproximado de sócios e de colaboradores, e sua composição quanto ao gênero e serviços oferecidos ou produtos comercializados (a fim de confirmar que se tratam de empresas desenvolvedoras de software). Após a coleta de dados, efetuou-se a análise e a discussão dos resultados, bem como traçou-se relações entre os resultados obtidos e as informações levantadas durante a revisão bibliográfica. Por fim, elencou-se desdobramentos para futuras pesquisas.

\footnotetext{
${ }^{2}$ Strings de busca são conjuntos de palavras-chave utilizados em uma revisão bibliográfica.

${ }^{3}$ Disponível em: <https://goo.gl/sDTovn>.
} 


\section{Resultados da pesquisa}

Ao todo, obteve-se 30 respostas ao questionário. Destas, cinco foram desconsideradas para este estudo, pois as empresas nas quais os profissionais atuam não são do setor de tecnologia, ou do setor privado, ou não estão localizadas na Grande Florianópolis. Optou-se por fazer esta seleção para comparar os dados obtidos na pesquisa com aqueles já existentes sobre o setor tecnológico privado da região. Salienta-se que um dos questionados afirmou não morar na região da Grande Florianópolis, mas nos Estados Unidos, trabalhando de modo remoto. Como a empresa está localizada na região de interesse da pesquisa, a resposta foi considerada. Assim, apresentamos a seguir os dados referentes ao montante de respostas válidas.

\subsection{Eixo 1 - dados pessoais}

Dentre as respostas válidas, $32 \%$ são de profissionais do gênero feminino e $68 \%$ do gênero masculino. Dos participantes, 4\% têm entre 16 e 25 anos, $76 \%$ entre 26 e 35 anos (incluindo-se neste grupo todas as mulheres), 16\% entre 36 e 45 anos, e outros $4 \%$ entre 46 e 55 anos.

Quanto à escolaridade, $80 \%$ dos questionados possui formação de nível superior ( $24 \%$ com graduação completa, $20 \%$ com pós-graduação incompleta e $36 \%$ com pós-graduação completa), enquanto $20 \%$ não possui graduação universitária (16\% possui graduação incompleta e $4 \%$ ensino médio completo). Entre os gêneros, cerca de $38 \%$ das mulheres participantes da pesquisa possui graduação completa e aproximadamente $62 \%$ delas pós-graduação completa, enquanto cerca de $29 \%$ dos homens possui até o ensino médio completo, $47 \%$ possui graduação completa, e $24 \%$ pósgraduação completa. Dentre os participantes da pesquisa sem graduação universitária, $60 \%$ atua como engenheiro/arquiteto de software ou programador, sendo todos eles do gênero masculino. Entre os profissionais graduados, por sua vez, cerca de 70\% atua na área de Design (Design, Design de Experiência do Usuário, Design de Interação). Dos que se identificaram como designer, cerca de $93 \%$ possui pelo menos graduação completa, e $60 \%$ atua com experiência do usuário ou design de interação.

Figura 1 - Dados pessoais dos profissionais participantes da pesquisa.

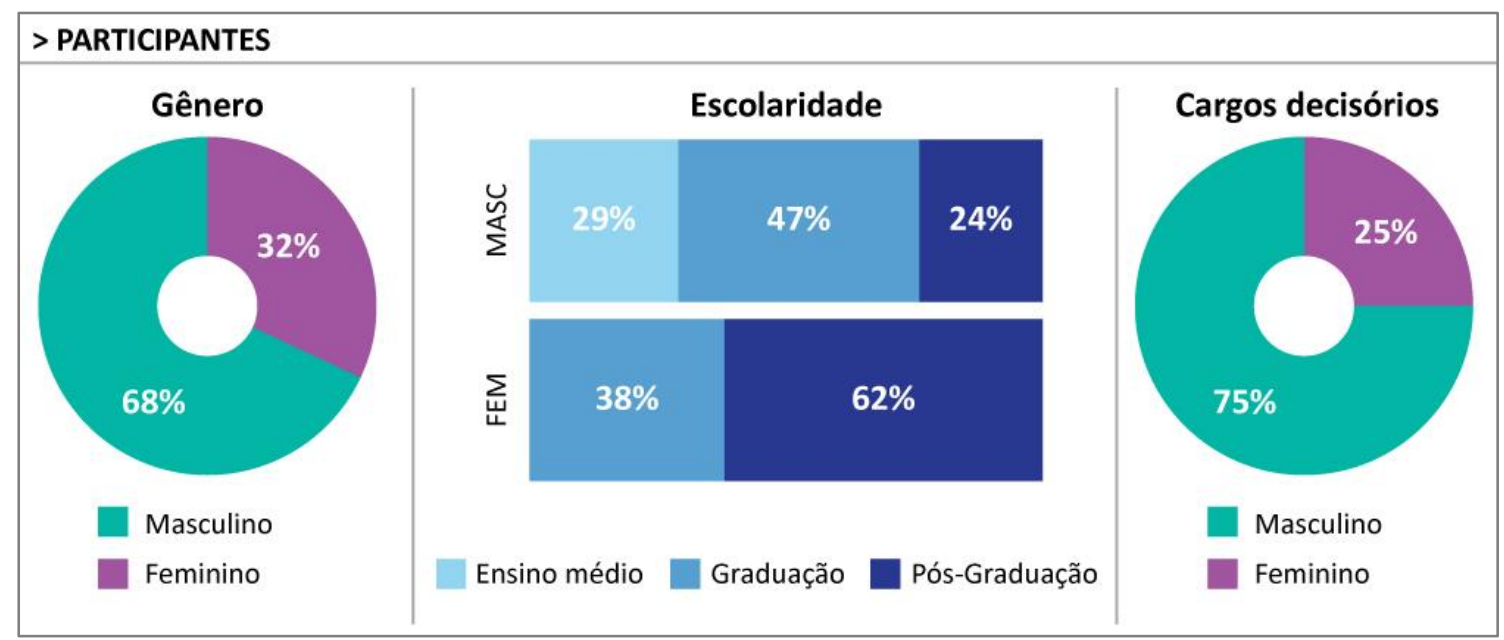

Fonte: Elaboração dos autores.

Entre as mulheres que participaram da pesquisa, mais da maioria (75\%) trabalha com 
experiência do usuário, seja como UX designers (User Experience designers - ou designers da experiência do usuário), UI designers (User Interface designers - ou designers de interface do usuário) ou consultoras na área. As demais (25\%) trabalham como designers (sem especificação de especialidade). Entre os participantes masculinos, cerca de $41 \%$ trabalha como engenheiro/arquiteto de software, programador ou analista de sistemas. Como designer (sem especificação) são aproximadamente $23,5 \%$, outros $23,5 \%$ como UX ou UI designers, $6 \%$ como gerente de projetos e $6 \%$ não identificou sua área de atuação, mas sim sua categoria funcional (como estagiário). Dentre todos os questionados, $48 \%$ possui algum tipo de cargo decisório (coordenação, chefia, direção ou similar). Destes, $75 \%$ são homens. Dentre os homens, cerca de $53 \%$ possui cargo decisório e, dentre as mulheres, aproximadamente $38 \%$.

Quanto à experiência profissional em desenvolvimento de softwares, $32 \%$ dos questionados possui até 3 anos de experiência, 12\% entre 4 e 6 anos, 24\% entre 7 e 9 anos e 32\% com 10 anos ou mais de experiência. Entre os profissionais mais experientes (com mais de 10 anos de prática), 75\% são homens, proporção que se repete na faixa com menos experiência (com até 3 anos de prática). Nas faixas intermediárias, temos mais equilíbrio entre a proporção de homens e mulheres: entre os que têm de 4 a 6 anos de experiência, cerca de $67 \%$ são homens e, entre os que possuem de 7 a 9 anos de experiência, há igualdade quanto ao número de profissionais homens e mulheres.

\subsection{Eixo 2 - dados da empresa}

As respostas válidas obtidas são de profissionais de empresas que possuem desde nenhum colaborador (formadas apenas pelos sócios) até cerca de 1.800 colaboradores contratados. Dentre elas, $28 \%$ são microempresas (possuem até 9 colaboradores), 20\% são pequenas empresas (de 10 a 49 empregados), 8\% são médias empresas (de 50 a 99 contratados) e $44 \%$ são grandes empresas (com 100 ou mais colaboradores).

Com relação ao quadro geral de colaboradores das empresas, em média, $63 \%$ são do gênero masculino, proporção similar a das empresas com quadro societário exclusivamente masculino, nas quais os homens ocupam aproximadamente $64 \%$ dos postos de trabalho. Nas empresas com quadro societário misto, a participação masculina no quadro de colaboradores é de $50 \%$. Nas empresas cujo quadro societário é não-masculino ${ }^{4}$, o quadro de colaboradores é formado por aproximadamente $46 \%$ de indivíduos masculinos (54\% não-masculinos). Uma das empresas possui um quadro de trabalhadores exclusivamente masculino, o que, somando-se às empresas que não possuem colaboradores, mas apenas sócios do gênero masculino, totaliza $12 \%$ das empresas com recursos humanos exclusivamente masculinos.

Sobre o quadro societário, as empresas inseridas na pesquisa possuem, em média, 3 sócios, sendo cerca de $84 \%$ deles do gênero masculino. Dentre as empresas, $76 \%$ possui apenas sócios do gênero masculino e $20 \%$ somente sócios não-masculinos. Uma única empresa (equivalente a $4 \%$ do total) possui configuração de gênero mista entre os sócios, sendo, neste caso, 75\% deles do gênero masculino. Assim, podemos afirmar que cerca de $80 \%$ das empresas inseridas na pesquisa possuem quadro societário predominantemente masculino.

\footnotetext{
${ }^{4}$ Foi utilizada neste trabalho a expressão "não-masculinos" para englobar os gêneros feminino, transgênero e outros diferentes de masculino, visto que no questionário foi solicitada apenas a quantidade de colaboradores e sócios do gênero masculino, a fim de facilitar o preenchimento do questionário pelos participantes.
} 
Figura 2 - Dados das empresas nas quais os participantes da pesquisa trabalham.

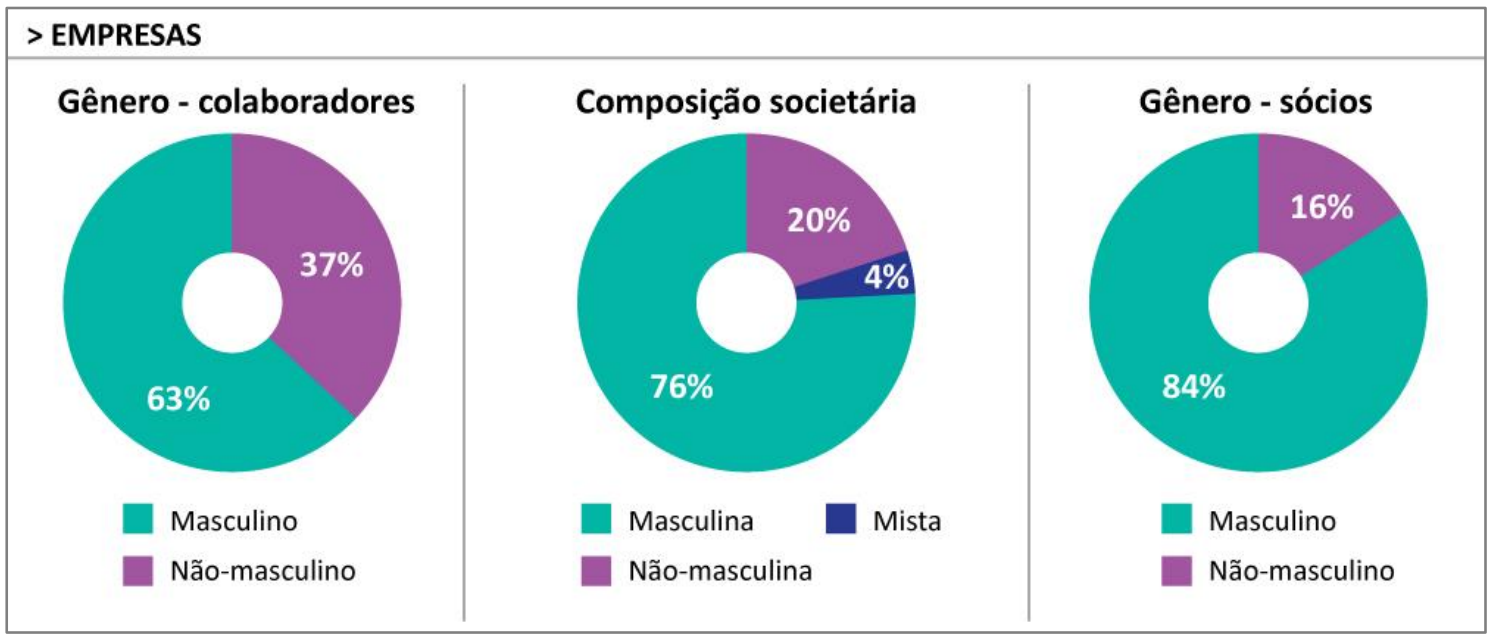

Fonte: Elaboração dos autores.

\subsection{Eixo 3-desenvolvimento de software}

Com relação aos métodos utilizados para o desenvolvimento de projeto, cujo questionário permitia múltiplas respostas, $24 \%$ dos participantes afirmou utilizar métodos de projeto intuitivos, baseados em experiências pessoais ou em projetos prévios, $48 \%$ afirmou utilizar métodos referenciais, desenvolvidos por profissionais ou empresas do setor, e outros $32 \%$ afirmou utilizar métodos exclusivos, desenvolvidos pela própria equipe ou empresa onde trabalha. Dois participantes ( $8 \%$ do total) afirmaram utilizar também métodos acadêmicos (desenvolvidos por pesquisadores da área), além dos métodos referenciais, embora, segundo um deles, o desenvolvimento de tais métodos geralmente não acompanhe as necessidades do mercado. Nenhum participante afirmou usar apenas métodos acadêmicos.

Quanto à formação das equipes para desenvolvimento de um software, $52 \%$ dos participantes afirma que ela se dá independentemente do perfil de público-alvo daquele produto. Já para os $48 \%$ restantes, a formação das equipes se dá justamente em função do público-alvo.

Em referência à tomada de decisão durante o desenvolvimento dos projetos, $44 \%$ dos participantes afirma que isso varia de acordo com a especificidade de cada projeto. Para $24 \%$, a opinião da maior parte da equipe decide, outros $20 \%$ afirma que o líder da equipe decide (embora isso possa ocorrer em apenas algumas etapas do projeto), $8 \%$ afirma que o cliente decide e ainda $4 \%$ afirma que os clientes ou pessoas externas à equipe/hierarquicamente superiores decidem (sócios ou diretores da empresa, por exemplo). Um dos participantes acrescentou que, ainda que a tomada de decisão varie de acordo com cada projeto, nos casos em que os prazos são mais limitados, os sócios ou diretores da empresa decidem. Outro afirma que os papéis decisórios variam de acordo com a complexidade envolvida em cada projeto.

No que se refere à comunicação e feedback, $16 \%$ dos profissionais afirmaram que as equipes utilizam também meios anônimos para que seus membros possam expressar opiniões, dar feedback aos colegas ou participar da tomada de decisão. Os demais não utilizam tais meios.

Todos afirmaram que acreditam ser necessário o envolvimento de representantes do público-alvo em alguma fase do projeto. Ao questionar-se se essa participação se dá na prática, $8 \%$ 
dos participantes afirma que ela nunca ocorre, $44 \%$ que ocorre eventualmente, $32 \%$ que ocorre com frequência e $16 \%$ que sempre ocorre a participação do público-alvo durante o desenvolvimento do software. A fim de complementar a pergunta anterior, questionou-se o porquê de, em determinados projetos, não ocorrer a participação do público-alvo (era possível escolher mais de uma opção de resposta). Dos profissionais que anteriormente afirmaram que em alguns projetos poderia não acontecer a participação do público-alvo, cerca de $10 \%$ diz existir dificuldade técnica para incluir o público-alvo no projeto devido à falta de experiência da equipe; $14 \%$ afirma que muitas vezes a participação não ocorre por opção dos clientes ou da própria empresa desenvolvedora que não vê necessidade em consultar o público-alvo, e outros $14 \%$ afirma ser difícil encontrar representantes do público-alvo para participar dos projetos. Entre os quesitos considerados mais relevantes para a não-participação do público-alvo, segundo os profissionais, estão o custo envolvido (incompatível com a verba do projeto) citado por $38 \%$ dos participantes, e, também, o tempo necessário para a participação do público-alvo, que dificultaria ou impossibilitaria o cumprimento dos prazos, citado por cerca de $43 \%$ dos profissionais ${ }^{5}$.

Figura 3 - Participação do público-alvo no desenvolvimento dos softwares.

\begin{tabular}{|c|c|c|}
\hline \multicolumn{3}{|l|}{ > PÚBLICO-ALVO } \\
\hline \multirow{6}{*}{$\begin{array}{l}\text { Participação do público-alvo } \\
\text { Nunca ocorre } \\
\text { Ocorre eventualmente } \\
\text { Ocorre com frequência } \\
\text { Sempre ocorre }\end{array}$} & \multicolumn{2}{|c|}{ Motivos citados para a não-participação do público } \\
\hline & Dificuldade técnica & $10 \%$ \\
\hline & $\begin{array}{l}\text { Opção dos clientes ou da } \\
\text { empresa desenvolvedora }\end{array}$ & $14 \%$ \\
\hline & $\begin{array}{l}\text { Dificuldade para encontrar } \\
\text { representantes do público-alvo }\end{array}$ & $14 \%$ \\
\hline & Custo & $38 \%$ \\
\hline & Tempo & $43 \%$ \\
\hline
\end{tabular}

Fonte: Elaboração dos autores.

Questionou-se também como se dá o envolvimento do público-alvo nos projetos, nos casos em que isso ocorre. Neste quesito, era possível escolher mais de uma opção de resposta. Segundo os profissionais que afirmaram incluir o público-alvo em alguma fase do projeto, pelo menos eventualmente, cerca de $91 \%$ deles afirma incluir o público na fase de teste, $83 \%$ na fase de planejamento, $43 \%$ na fase de implementação, $35 \%$ durante o desenvolvimento propriamente dito e $4 \%$ após a implementação (obtendo feedback com relação ao uso do produto final). Cerca de $17 \%$ afirma incluir o público somente em uma fase, sendo metade deles apenas na fase de teste ou na fase de planejamento. Os demais (cerca de $83 \%$ ), buscam envolver o público em pelo menos duas

\footnotetext{
${ }^{5}$ Entre as respostas obtidas para esta questão, $16 \%$ foram incoerentes: aqui, alguns profissionais afirmaram que tal questão não se aplica porque sempre incluem o público-alvo no desenvolvimento do software, sendo que anteriormente haviam afirmado que os incluíam com frequência. Desta forma, tais participantes não explicitaram o motivo pelo qual o público-alvo poderia não ser incluído nos projetos.
} 
etapas do projeto, sendo uma delas sempre a fase de teste.

Com relação às maneiras como pode se dar o envolvimento do público-alvo ${ }^{6}$, para aqueles que afirmam incluir o usuário no projeto, ainda que eventualmente, cerca de $78 \%$ afirma o incluir de maneira consultiva (o usuário é consultado para avaliar e emitir uma opinião sobre o projeto em andamento), 70\% de maneira informativa (o público-alvo serve como fonte de informação, obtida por entrevistas, questionários ou observação) e $26 \%$ de maneira participativa (quando a empresa transfere para o público-alvo o poder sobre decisões de projeto). Dentre os que afirmaram sempre envolver o público no projeto, metade o faz apenas de maneira informativa e metade engloba as maneiras informativa, consultiva e participativa. Entre os participantes que incluem o usuário no desenvolvimento dos projetos, $43 \%$ afirma que isso ocorre apenas de uma forma. Dentre estes casos, $60 \%$ inclui o público de maneira exclusivamente consultiva e $40 \%$ de maneira exclusivamente informativa.

Com relação ao comportamento dos profissionais durante o desenvolvimento do projeto, $80 \%$ deles alega se sentir mais à vontade ou seguro ao desenvolver um software cuja utilização tem relação com o seu próprio cotidiano e suas experiências pessoais; $92 \%$ afirmam emitir mais opinião ou participar mais ativamente do projeto quando o software em desenvolvimento tem relação com o seu próprio cotidiano e suas experiências pessoais e outros $92 \%$ afirmam utilizar suas experiências pessoais como referência para a tomada de decisão.

No que diz respeito à especificidade dos públicos, questão que permitia múltiplas escolhas, $96 \%$ dos participantes afirmam ter desenvolvido ou estar desenvolvendo softwares para adultos de qualquer gênero, $40 \%$ para crianças de qualquer gênero e, também, $40 \%$ para adolescentes de qualquer gênero. Apenas $20 \%$ dos profissionais alega desenvolver ou ter desenvolvido software para algum gênero específico, dentre os quais softwares para pessoas com qualquer idade, mas com gênero específico (feminino ou masculino), softwares para adultos do gênero feminino, softwares para adultos do gênero masculino e softwares para adolescentes do gênero feminino. Destes profissionais, $80 \%$ é do gênero feminino. Apenas cerca de $6 \%$ dos profissionais do gênero masculino (equivalente a $4 \%$ de todos os participantes) desenvolve ou já desenvolveu produtos para público de gênero específico (sendo, nestes casos, públicos femininos). Entre as profissionais do gênero feminino, $50 \%$ (equivalente a $16 \%$ de todos os participantes) desenvolve ou já desenvolveu softwares para públicos de gênero específico, tanto feminino quanto masculino. ${ }^{7}$

Questionou-se também a respeito da composição das equipes de desenvolvimento, quanto ao gênero. Dentre todos os participantes, 52\% acreditam que a composição da equipe de desenvolvimento, no que diz respeito ao gênero (masculino, feminino ou outro) influencia no resultado do projeto, $44 \%$ discorda e $4 \%$ não tem opinião formada a respeito. Dos que discordam ou não têm opinião formada, $83 \%$ são do gênero masculino. Entre as participantes do gênero feminino, $75 \%$ acreditam que a composição da equipe influencia no resultado do projeto e $41 \%$ dos profissionais masculinos afirmam o mesmo.

\footnotetext{
${ }^{6}$ Utilizou-se no questionário a classificação proposta por Cybis et al. (2010), na qual o envolvimento do público-alvo em um projeto pode se dar de maneira informativa, consultiva ou participativa.

7 Uma das respostas obtidas com relação a este fator foi incoerente, visto que a profissional inicialmente afirmou desenvolver softwares para públicos majoritariamente femininos ou masculinos e posteriormente afirmou desenvolver softwares apenas para público masculino.
} 
Figura 4 - Público-alvo atendido pelos profissionais participantes da pesquisa

\begin{tabular}{|c|c|c|}
\hline \multicolumn{3}{|l|}{ > PÚBLICO-ALVO } \\
\hline \multirow{9}{*}{$\begin{array}{l}\text { Projetaram apenas para público com gênero específico } \\
\text { Projetaram tanto para público com gênero específico } \\
\text { quanto "neutro" } \\
\text { Projetaram apenas para público com gênero "neutro" }\end{array}$} & \multicolumn{2}{|c|}{ Categorias de público citadas pelos profissionais } \\
\hline & Adulto feminino & $4 \%$ \\
\hline & Adulto masculino & $4 \%$ \\
\hline & Qualquer idade feminino & $8 \%$ \\
\hline & Qualquer idade masculino & $8 \%$ \\
\hline & Crianças "gen. neutro" & $40 \%$ \\
\hline & & \\
\hline & Adolescentes "gen. neutro" & $40 \%$ \\
\hline & Adultos "gen. neutro" & $96 \%$ \\
\hline
\end{tabular}

Fonte: Elaboração dos autores

Todos os participantes afirmaram sentirem-se confortáveis para emitir sua opinião durante o desenvolvimento dos projetos, independentemente das pessoas que compõem a equipe, inclusive quando a maioria dos colegas é de gênero diferente do seu, sendo que $8 \%$ diz adaptar a maneira de como se comunica de acordo com as pessoas envolvidas.

\section{Análise dos resultados}

As respostas válidas obtidas com o questionário ensejam algumas reflexões que podem, inclusive, servir para pesquisas posteriores mais amplas e aprofundadas. Primeiramente, com relação à proporção entre os gêneros dos participantes: $68 \%$ são do gênero masculino, número maior do que o estimado pela Acate (2016) com relação à composição das empresas de tecnologia catarinenses (61,6\% de colaboradores masculinos), e menor do que o estipulado para os mercados tecnológicos brasileiro e americano (na faixa dos $80 \%$ de participação masculina).

No questionário, havia a possibilidade de os participantes identificarem seu gênero como masculino, feminino, transgênero ou outro (podendo complementar essa informação). Todos os questionados responderam dentro do binarismo masculino/feminino. Com isso, pode-se levantar o questionamento a respeito da diversidade existente nas empresas de tecnologia e na existência ou não de acesso aos postos de trabalho para profissionais que não se enquadram nos modelos de gênero comumente estabelecidos. Para futuros estudos, recomenda-se tratar também de outras diversidades no ambiente de trabalho do setor tecnológico, considerando-se fatores como origem, etnia, renda, deficiências, entre outras.

Pode-se perceber, a partir das respostas obtidas, que as mulheres se encontram dentro do grupo mais jovem (entre 26 e 35 anos), mas não necessariamente menos experiente ou habilitado: todas as participantes possuem formação de nível superior (tendo 62\% delas também pósgraduação), destacando-se dos profissionais masculinos, entre os quais cerca de $29 \%$ não possuem graduação. Tal fato poderia indicar algumas tendências do setor: a primeira delas seria a existência de algum nível de desigualdade nos quesitos de seleção das empresas, no qual as mulheres precisariam de um diploma para provarem sua competência técnica e ingressarem na área; a outra 
possibilidade seria a de as mulheres simplesmente valorizarem mais a formação acadêmica, ou ainda de terem mais acesso a ela. Segundo o IBGE (2018), a maior diferença entre a escolaridade de homens e mulheres se dá com relação ao nível superior completo e na faixa etária mais jovem, entre 25 e 44 anos de idade, na qual $21,5 \%$ das mulheres possui graduação, ante $15,6 \%$ dos homens. Ao se comparar esses dados com os obtidos nesta pesquisa, percebe-se que, tanto homens quanto mulheres do setor de desenvolvimento de softwares da Grande Florianópolis possuem nível de formação muito superior à média nacional. Ainda assim, como aponta o IBGE (2018), mesmo que as mulheres apresentem os melhores resultados educacionais, ainda não obtiveram resultados compatíveis com sua qualificação, no mercado de trabalho, o que podemos observar também no setor de desenvolvimento de softwares catarinense, onde homens ocupam $75 \%$ dos cargos decisórios ou de gestão, o que deve elevar, também, a remuneração média masculina no setor. 0 fator racial relacionado ao gênero e educação, segundo o IBGE (2018) evidencia algumas outras relações que não foram consideradas nesta pesquisa, como o maior acesso das mulheres brancas ao ensino superior, enquanto as mulheres pretas ou pardas ainda se encontram em desvantagem de 10 pontos percentuais com relação aos homens brancos.

Analisando-se a área de atuação dos profissionais, percebe-se que há um cenário acessível em experiência do usuário ou design de interação para atuação de mulheres e profissionais formados em Design. Outro fato a se destacar é que cerca de $93 \%$ dos profissionais que se identifica como designer possui pelo menos graduação completa na área, o que demonstra como este campo recebeu reconhecimento do setor de desenvolvimento de software, havendo poucos profissionais autodidatas trabalhando como designers nesses setores, ainda que a profissão não seja regulamentada. Com relação aos profissionais de engenharia de software, $100 \%$ dos pesquisados são homens, o que enseja também o questionamento quanto ao acesso de mulheres às áreas correlatas. Cerca de $43 \%$ desses profissionais não possui graduação completa, fato que poderia demonstrar um viés da própria profissão, que talvez não credite ao diploma de graduação uma exigência para a contratação de profissionais, mas sim valorização em sua experiência, pois $57 \%$ dos participantes da pesquisa, que atuam em áreas correlatas à engenharia de software, possui 10 anos ou mais de experiência profissional.

Um dos questionados afirmou não morar na região da Grande Florianópolis e sim nos Estados Unidos, ainda que a empresa esteja localizada na região de interesse da pesquisa. Tal fato exemplifica uma das modalidades de atuação dos profissionais da área de desenvolvimento de software, que é o trabalho remoto, podendo também indicar a existência de acordos flexíveis de trabalho nesse setor.

Dentre os sócios das empresas enumerados pelos profissionais que responderam ao questionário, $84 \%$ são do gênero masculino, ante os 74,5\% estipulado pela Acate (2016) para as empresas de tecnologia do estado, o que indica maior participação dos empreendedores masculinos nas empresas de desenvolvimento de software na Grande Florianópolis. Com relação à idade, 76\% dos participantes têm entre 26 e 35 anos, ficando dentro da faixa estipulada para a idade média dos colaboradores do setor em Santa Catarina (32 anos).

Com relação à hierarquia dos postos ocupados, observa-se grande disparidade entre os gêneros, já que $75 \%$ dos que possuem cargos decisórios são homens, sem considerarmos os postos societários. Ainda assim, o cenário observado revela-se mais igualitário do que o estipulado por Williams (2014) nos Estados Unidos, onde 90\% dos cargos decisórios ou de gestão seriam ocupados por homens. Com relação ao cenário nacional brasileiro, no qual $62,2 \%$ dos cargos gerenciais são 
ocupados por homens, segundo o IBGE (2018), o setor de desenvolvimento de softwares da Grande Florianópolis mostra-se, portanto, menos igualitário. Outro dado exemplifica a desigualdade na composição das empresas relacionadas aos participantes da pesquisa: $12 \%$ delas possuem recursos humanos exclusivamente masculinos, sem participação alguma de outros gêneros no quadro societário e no quadro de colaboradores.

Percebe-se, também, a predominância masculina no quadro societário das empresas inseridas na pesquisa, nas quais cerca de $84 \%$ dos sócios são homens e $76 \%$ delas possuem apenas sócios do gênero masculino. É possível observar, a partir dos dados coletados, que o quadro societário parece influenciar a composição de colaboradores da empresa, no que diz respeito ao gênero, já que nas empresas de quadro societário exclusivamente masculino, os homens ocupam aproximadamente $63 \%$ dos postos de trabalho, já nas de quadro societário não-masculino, a diferença é menor: cerca de $54 \%$ dos colaboradores também são não-masculinos. Nas situações em que o quadro societário é misto, essa proporção passa a se igualar, levando a participação masculina para cerca de $50 \%$ dos colaboradores. Tal cenário poderia indicar que um quadro societário misto facilitaria a obtenção de maior igualdade de gênero na composição das empresas.

Com relação ao desenvolvimento dos softwares, pode-se observar que $80 \%$ dos profissionais participantes da pesquisa utilizam pelo menos um método de projeto que vai além do processo intuitivo. Destes, apenas 10\% não possui graduação completa. Entre os profissionais que afirmaram usar apenas métodos intuitivos, $60 \%$ não possui formação universitária. Dos que afirmaram utilizar métodos exclusivos, cerca de $87 \%$ é designer. Tal resultado indica que a formação universitária dos profissionais que trabalham com desenvolvimento de softwares leva em consideração a aplicação de métodos de projeto. Os profissionais da área de design, por sua vez, parecem capacitados também para desenvolverem seus próprios métodos. No entanto, métodos desenvolvidos por pesquisadores da área acadêmica são utilizados por somente $8 \%$ dos participantes da pesquisa, 0 que demonstra existir uma lacuna entre o que é produzido na academia e o que é utilizado pelos profissionais de desenvolvimento de softwares, podendo ser este também um campo para futuros estudos.

Quanto à formação das equipes para desenvolvimento de um determinado software, $48 \%$ dos participantes da pesquisa afirma que ela se dá em função do público-alvo de cada produto. Considerando-se que a maioria dos colaboradores das empresas inseridas na pesquisa são homens, é possível inferir que o público-alvo dos produtos desenvolvidos por, pelo menos, metade dessas empresas seria majoritariamente masculino. No entanto, segundo os profissionais participantes, apenas $12 \%$ afirmou estar desenvolvendo ou já ter desenvolvido produtos especificamente para pessoas do gênero masculino. Tais dados ensejam o questionamento a respeito da maneira como as equipes são formadas e a possível influência dessa formação no resultado final do projeto, visto que $52 \%$ dos profissionais acreditam que a composição da equipe de desenvolvimento, no que diz respeito ao gênero, influencia no resultado do projeto. Com relação a este ponto, especificamente, é possível perceber disparidade de percepção entre profissionais mulheres e homens: $75 \%$ delas acredita que a composição da equipe influencia no resultado do projeto, ante $41 \%$ deles. Tal visão masculina a respeito de sua influência no resultado final do produto, no que diz respeito a vieses de gênero poderia explicar a manutenção de equipes majoritariamente masculinas (por gerentes também em sua maioria masculinos), visto que eles não acreditam ser esse um fator relevante para o desenvolvimento do produto. De alguma maneira, as mulheres que participam do desenvolvimento de softwares na Grande Florianópolis percebem a influência do gênero dos 
profissionais no resultado final do projeto, mas não foi possível verificar, nesta pesquisa, o porquê delas perceberem tal fato ou como isso ocorre ou, ainda, se isso realmente ocorre.

De mesmo modo, não há consenso, entre os participantes da pesquisa, sobre a tomada de decisão durante os projetos. Para $44 \%$ ela varia de acordo com cada projeto e, para os demais, ela pode ser tomada pelo cliente, pela equipe, por sócios ou diretores, ou pelos líderes da equipe. Quando participam da tomada de decisão, 92\% dos participantes afirma utilizar suas experiências pessoais como referência. Além disso, $80 \%$ sente-se mais à vontade ou seguro ao desenvolver um software relacionado com o seu próprio cotidiano e suas experiências pessoais, situação em que também participam mais ativamente dos projetos. Sendo assim, é possível questionar, novamente, qual seria o impacto no resultado dos projetos direcionados a pessoas de qualquer gênero ou de gênero feminino, quando desenvolvidos por essas equipes majoritariamente masculinas, já que há a tendência, segundo os participantes, em utilizar suas experiências pessoais como referência.

Todos os participantes da pesquisa afirmaram que acreditam ser necessário envolver representantes do público-alvo em alguma fase do projeto. No entanto, $76 \%$ afirma que isso nem sempre ocorre e $8 \%$ deles afirma que isso nunca ocorre. Dentre os fatores citados para a nãoparticipação do público-alvo nos projetos, destaca-se o tempo, elencado por cerca de $43 \%$ dos profissionais, o que pode indicar uma tendência mercadológica de se exigir o desenvolvimento dos softwares em períodos de tempo insuficientes para garantir seu bom desempenho junto ao usuário final. Williams (2014) aborda a questão afirmando que, muitas vezes, a tomada de decisão em projetos de software se dá de maneira rápida, devido à pressão dos prazos de entrega do produto, induzindo os profissionais a tomarem decisões espontâneas, baseadas em intuição, nas suas experiências e opiniões pessoais. Juntando-se a esse cenário o fato de a maioria dos cargos decisórios serem ocupados por homens, a autora afirma ser possível considerar que boa parte dos softwares é desenvolvida com um viés masculino, ainda que os profissionais não tenham essa intenção. Comparando-se tal visão aos dados obtidos por meio do questionário aplicado para esta pesquisa, pode-se acreditar que isso deva ocorrer de maneira semelhante no cenário da Grande Florianópolis, ainda que os profissionais busquem incluir o público-alvo no desenvolvimento dos projetos, o que efetivamente não está ocorrendo.

Outro fator a ser destacado é que $96 \%$ dos profissionais afirma ter desenvolvido, ou estar desenvolvendo, softwares direcionados a pessoas de qualquer gênero. Ou seja, existe a intenção, por parte da maioria dos profissionais, de desenvolverem os chamados "softwares de gênero neutro". Sendo assim, torna-se relevante investigar, em futuras pesquisas, de que maneira se busca desenvolver esses softwares sem vieses de gênero e se esse objetivo é efetivamente alcançado.

Todos os participantes da pesquisa afirmam que se sentem confortáveis para emitir sua opinião durante o desenvolvimento de projetos, independentemente da composição das equipes, mesmo que a maioria seja de gênero diferente do seu. Tal cenário poderia justificar o fato de $84 \%$ das equipes onde esses profissionais estão inseridos não utilizarem meios anônimos para que seus membros possam expressar opiniões, dar feedback aos colegas ou participar da tomada de decisão; o que é citada por Williams (2014) com o uma forma de facilitar a participação das mulheres nos projetos, especialmente quando estão em minoria ou se sentem intimidadas pelos colegas.

\section{Conclusão}

A revisão bibliográfica realizada no início desta pesquisa serviu de maneira satisfatória como embasamento para a elaboração do questionário aplicado na coleta de dados. Por sua vez, a 
aplicação do questionário possibilitou observar, de maneira geral, o cenário de desenvolvimento de softwares na Grande Florianópolis, no que tange às questões de gênero e os métodos de projeto. Em linhas gerais, foi possível perceber correlações entre o observado no cenário norte-americano, com o apontado por Williams (2014), visto que as empresas inseridas nesta pesquisa possuem quadro societário, de gestão e de colaboradores, majoritariamente masculino, ainda que o públicoalvo de seus projetos seja predominantemente de gênero neutro. As empresas da Grande Florianópolis apresentam dificuldade em garantir a participação do público-alvo no desenvolvimento dos projetos e são acometidas por fatores como o curto espaço de tempo para a entrega dos projetos, o que muitas vezes leva os gestores a tomarem decisões rápidas e espontâneas, baseadas em sua experiência pessoal. Tal cenário possibilitaria, como apontado por Williams (2014), o desenvolvimento de softwares com viés masculino, ainda que os profissionais não tenham essa intenção.

A partir das respostas obtidas, pode-se verificar que há questões ainda pouco esclarecidas, tornando-se este um campo fértil para a realização de novas pesquisas, em especial nas áreas de Design, Ergonomia Organizacional, Método Projetual, Desenvolvimento de Software e Questões de Gênero. Entre as possibilidades para futuras pesquisas, pode-se incluir: (1) ao abordar as questões metodológicas e a composição das equipes do setor tecnológico, tratar também de outras diversidades no ambiente de trabalho, considerando-se origem, etnia, renda, deficiências, entre outras; (2) investigar possíveis desigualdades nos critérios de seleção aplicados a homens e mulheres no setor de tecnologia, assim como aos critérios utilizados na seleção de profissionais de Engenharia de Software com relação a outras áreas, como o Design; (3) investigar fatores que possam dificultar o acesso das mulheres a profissões correlatas à Engenharia de Software e ao empreendedorismo no setor tecnológico; (4) buscar compreender os fatores que levam as empresas do setor tecnológico a contratar e oferecer cargos decisórios predominantemente aos homens; (5) investigar se há, efetivamente, alguma relação entre a composição do quadro societário das empresas e a composição do quadro de colaboradores, no que diz respeito ao gênero; (6) desenvolver maneiras para aproximar o meio acadêmico do mercado de tecnologia, de forma a se aproveitar e implementar as pesquisas desenvolvidas; (7) compreender de que maneira as empresas buscam desenvolver os softwares a fim de que eles sejam neutros e sirvam para todos os gêneros; e (8) verificar a abordagem metodológica dos profissionais ao desenvolverem softwares para gêneros específicos.

Entende-se, ainda, que é relevante ampliar o alcance da pesquisa, a fim de se comparar os resultados obtidos na região da Grande Florianópolis com outras regiões do Brasil, por exemplo. Além disso, os resultados obtidos com esta pesquisa poderiam servir como embasamento para a elaboração de entrevistas semi-estruturadas com profissionais da área de Desenvolvimento de Software, objetivando confrontar e aprofundar os resultados obtidos com o questionário previamente aplicado. 


\section{Referências}

ACATE, Associação Catarinense de Empresas de Tecnologia. ACATE Tech Report 2015: Panorama de Inovação e Tecnologia de SC. Florianópolis: Acate, 2016.

BARDZELL, Shaowen et al. Feminism and Interaction Design. In: ANNUAL CHI CONFERENCE ON HUMAN FACTORS IN COMPUTING SYSTEMS, 29., 2011, Vancouver. Proceedings...

BRESLIN, Samantha; WADHWA, Bimlesh. Exploring nuanced gender perspectives within the $\mathrm{HCl}$ community. In: ACM INTERNATIONAL CONFERENCE, 2014. Proceedings...

BURNETT, M.M. et al. SIG - Gender-inclusive software: What we know about building it. In: ANNUAL CHI CONFERENCE ON HUMAN FACTORS IN COMPUTING SYSTEMS, 33., 2015, Seul. Proceedings... p. 857-860.

CASTRO, Bárbara Geraldo. Afogados em contratos: o impacto da flexibilização do trabalho nas trajetórias dos profissionais de TI. 2013. Tese (Doutorado em Ciências Sociais) - Instituto de Filosofia e Ciências Humanas, Unicamp, Campinas, 2013.

CHURCHILL, Elizabeth F. Sugared Puppy-Dog Tails: Gender and Design. Interactions, Nova lorque, v. 17, n. 2, p. 52-56, mar. 2010.

CYBIS, Walter et al. Ergonomia e usabilidade: conhecimentos, métodos e aplicações. São Paulo: Novatec Editora, 2010.

DRAY, Susan M. et al. Perspectives on gender and product design. In: ANNUAL ACM CONFERENCE ON HUMAN FACTORS IN COMPUTING SYSTEMS, 32., 2014, Toronto. Proceedings... p. 53-56.

GROSSI, M. P. Identidade de Gênero e Sexualidade. Antropologia em Primeira Mão. Florianópolis, p. 1-18, 1998 (versão revisada - 2010). Disponível em:

<https://repositorio.ufsc.br/bitstream/handle/123456789/1205/identidade_ genero_revisado.pdf?sequence=1\&isAllowed=y>. Acesso em: 9 set. 2017.

HORTA NUNES, Jordão. Gênero e raça no trabalho em tecnologia da informação (TI). Ciências Sociais Unisinos, São Leopoldo, v. 52, n. 3, p. 383-395. 2016.

IBGE, Instituto Brasileiro de Geografia e Estatística. Estatísticas de Gênero: Indicadores sociais das mulheres no Brasil. Rio de Janeiro: IBGE, 2018.

KEARNEY, Mary Celeste. Pink Technology: Mediamaking Gear for Girls. Camera Obscura, Durham, v. 25, n. 2. 2010.

OLINTO, Gilda. A inclusão das mulheres nas carreiras de ciência e tecnologia no Brasil. Inclusão Social, Brasília, v. 5 n. 1, p.68-77, jul./dez. 2011.

RATZER, Brigitte et al. Bringing Gender into Technology: A Case Study in User-Interface-Design and the Perspective of Gender Experts. International Journal of Gender, Science and Technology, v. 6, n. 1, p. 3-24. 2014.

SCHLESINGER, Ari et al. Intersectional $\mathrm{HCl}$ : Engaging Identity through Gender, Race, and Class. In: CHI CONFERENCE ON HUMAN FACTORS IN COMPUTING SYSTEMS, 2017, Denver. Proceedings... p. 5412-5427.

WILLIAMS, Gayna. Are you sure your software is gender-neutral? Interactions, Nova lorque, v. 21, n. 1. p. 36-39, jan./fev. 2014. 